\title{
Energy saving measures on pneumatic drive systems
}

\author{
J. Hepke, J. Weber \\ Institute of Fluid Power (IFD), Dresden University of Technology, Dresden, Germany \\ E-mail: hepke@ifd.mw.tu-dresden.de,weber@ifd.mw.tu-dresden.de
}

\begin{abstract}
In this article two different energy saving measures are presented. The possible savings potential and the effort of realizing these methods are described. Using these measures it was shown, that up to $55 \%$ energy saving could be achieved for a single drive.

The paper presents the thermodynamic principles that are needed to determine the energy consumption of pneumatic drives, which consist of the compressed air and the exergy analysis calculations. Further on, the influence of the design parameters on the energy consumption has been studied. Possible savings solutions have been arranged and brought together to provide and exemplary overview. In this case two savings methods were realized on a single cylinder drive of a pneumatic handling system.

These selected energy saving solutions aim at the optimization of the design parameters of pneumatic cylinder drives and on the use of exhaust air recovery circuits. The use of these saving measures is first tested via simulation and then implemented on an example cylinder drive. For each saving measure the influence on the energy consumption and on the motion profile of the drive is investigated in detail. Focus was especially directed to the question, whether the original motion profile of the example drive remained the same after applying the saving measures.
\end{abstract}

Keywords: pneumatic drive systems, energy saving measures, optimization of the design parameters, exhaust air recovery circuit, pay-back period

\section{Introduction}

The field of industrial automation requires the realization of complex handling tasks. In order to solve them, handling systems with pneumatic and electric drives are being used. Pneumatic drives require only low investment and maintenance costs and distinguish themselves through a flexible and robust design. They have to handle different operating tasks with a large range of forces, strokes and operating times.

In most cases handling tasks can be realized using pneumatic as well as electric drives. In this competition energy costs of the drive technology become more and more important. Compressed air is an expensive source of energy. To increase the competitiveness of pneumatic drives the compressed air consumption has to be reduced.

There are several energy saving measures, however only a few give a concrete statement about the correlation between potential energy savings and implementation costs.

The paper gives an overview about possible energy saving measures for pneumatic drives. Two of these saving measures will be investigated experimentally and simulation-based. Drawing on the example of a standard exhaust-air-flow-controlled cylinder drive the achieved energy saving, the effort for implementing these measures as well as the resulting pay-back period will be shown in the following chapters.

\section{Theoretical approaches for determining energy consumption of pneumatic drives}

There are different methods known for quantifying the energy demand of pneumatic drive systems, i.e. a compressed air consumption calculation and an exergy analysis. Moreover a calculation based on the "air power" can be performed [1]. This approach can be derived from the formula of the technical work at a cylinder as well as from the exergy flow under the assumption of isothermal conditions (instant temperature equalization). This method is excluded from this paper.

\subsection{Compressed air consumption calculation}

The first approach is a compressed air consumption calculation [2], which is a simplified method for calculating the energy consumption of pneumatic drives. It can only be 
used for standard systems like an exhaust-air-flowcontrolled cylinder drive. This method considers the compressed air that is needed for filling the different volumes. This compressed air is required for the compression processes within the tube and dead volumes and for the realization of the cylinder's stroke. To calculate the energy consumption for a double stroke of a standard cylinder drive by using the first method, fig. 1 shows the required equations.

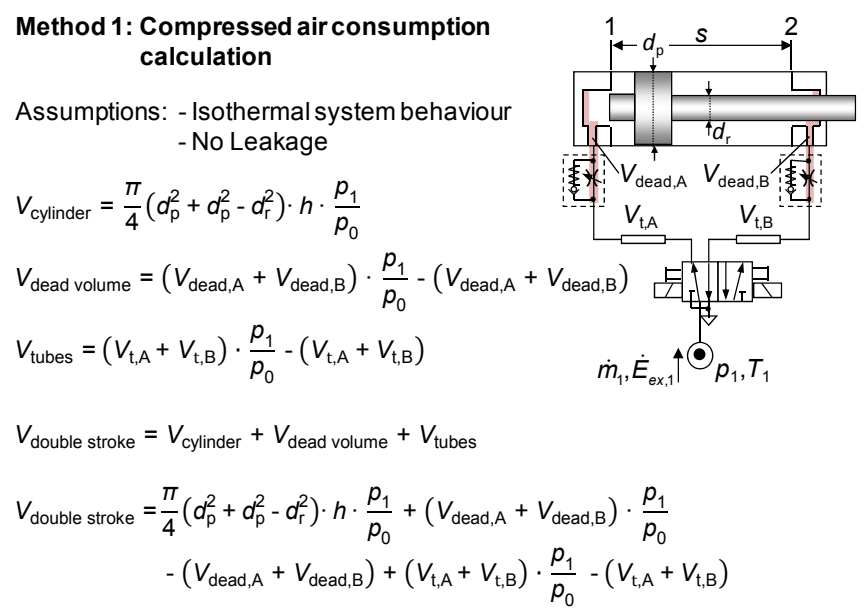

Figure 1: Compressed air consumption for a double stroke $(1 \rightarrow 2+2 \rightarrow 1)$ of a standard cylinder drive

The calculation formula is based on a summation of the filling volumes and the pressure levels. Hence this equation compares the initial thermodynamic state, within the filling volumes, with the thermodynamic state after completing the motion of the piston. Therefore this method isn't suitable for quantifying energy losses during the thermodynamic processes.

The tube and dead volumes are filled with compressed air starting at ambient pressure level $p_{0}$ whereas the cylinder chambers are filled starting at the null volume. Under the assumption of isothermal system behaviour (instant temperature equalization with the ambient air) and no leakage occurrence the compressed air consumption only depends on the filling volumes and pressure levels. However technical thermodynamic systems typically show polytropic changes in values of state variables. Compression processes that are occurring during such a state change are characterized by a temperature increase, which is accompanied by a pressure increase. As a result less mass flow is required for the pressure build-up within the filling volume.

The neglect of the temperature behaviour is an error in the air calculation, which can be estimated by investigating the air consumption of a drive with shifting heat exchange conditions. This experiment can be virtually done. The heat exchange conditions depend on the thermal transmittance of the cylinder wall as well as tube walls and on the operating times of the drive. A drive with short operating times and for this reason short dwell times will show approximately adiabatic thermal behaviour, since there is no time for heat transfer with the surroundings. In the next step the heat transfer condition of the cylinder wall and tube walls is varied from isothermal ( $n=1$, instant heat exchange with the ambience) to polytropic $(n=1,1)$ and finally to adiabatic ( $n=1,4=\kappa$, no heat exchange with the ambience). This experiment shown in fig. 2 demonstrates that the compressed air consumption of a system with isothermal and adiabatic thermodynamic changes differs about $16 \%$. Thus this error normally causes differences between the calculated and the actually consumed compressed air.
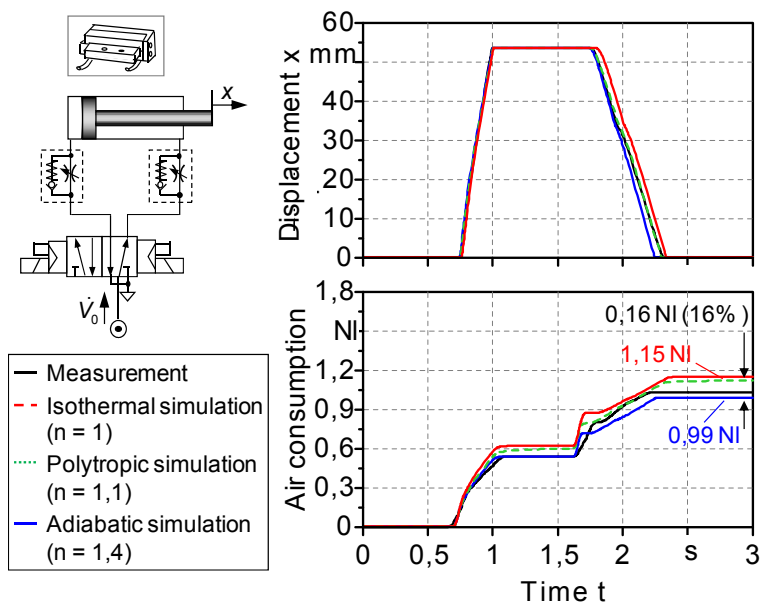

Figure 2: Compressed air consumption for a cylinder drive with changing heat transfer conditions

In case of an energy saving drive structure with a modified circuit structure (exhaust-air recovery circuit) or a modified valve control strategy the volumes are filled with compressed air up to an unknown pressure level that is lower than the working pressure. For these drive structures a compressed air calculation cannot be performed. For this purpose a system simulation that is more complex has to be done for the determination of the energy consumption.

In contrast to the second method a compressed air calculation is less complex and more practical than determining the exergy.

\subsection{Exergy analysis}

The second method represents an exergy analysis [3]. For this analysis equations are needed, that are based on the first and second law of thermodynamics. This method is much more complex than the compressed air consumption calculation, but implies all forms of energy (heat etc.) and enables a self-contained energy balancing within a system. Figure 3 shows the equations that are required for calculating the exergy flows at certain observation points and the exergy consumption for a double stroke of a standard cylinder drive. 
Method 2: Exergy analysis

- Observation point

Exergy flow at a certain observation point

$\dot{E}_{\mathrm{ex}, \mathrm{i}}=\dot{m}_{\mathrm{i}} \cdot\left(c_{\mathrm{p}} \cdot T_{0}-c_{\mathrm{p}} \cdot T_{\mathrm{i}}\right)$

$$
-\dot{m}_{\mathrm{i}} \cdot T_{0} \cdot\left(-c_{\mathrm{p}} \cdot \ln \frac{T_{\mathrm{i}}}{T_{0}}+R \cdot \ln \frac{p_{\mathrm{i}}}{p_{0}}\right)
$$

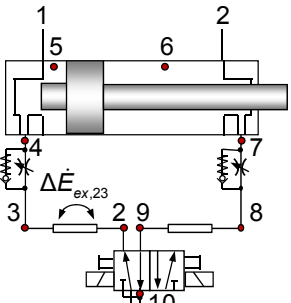

Exergy consumption for a double stroke of the cylinder drive 10

$$
\begin{aligned}
E_{\text {ex }, 1}= & \int_{\text {double stroke }} \dot{m}_{1} \cdot\left(c_{\mathrm{p}} \cdot T_{0}-c_{\mathrm{p}} \cdot T_{1}\right) \cdot d t \\
& -\int_{\text {double stroke }} \dot{m}_{1} \cdot T_{0} \cdot\left(-c_{\mathrm{p}} \cdot \ln \frac{T_{1}}{T_{0}}+R \cdot \ln \frac{p_{1}}{p_{0}}\right) \cdot d t
\end{aligned}
$$

Exergy flow difference between certain observation points (including leakage)

$$
\begin{aligned}
\Delta \dot{E}_{\mathrm{ex}, \mathrm{j}}= & \dot{m}_{\mathrm{j}} \cdot c_{\mathrm{p}} \cdot T_{j}-\dot{m}_{\mathrm{i}} \cdot c_{\mathrm{p}} \cdot T_{\mathrm{i}} \\
& +\dot{m}_{\mathrm{i}} \cdot T_{0} \cdot c_{\mathrm{p}} \cdot \ln \frac{T_{\mathrm{i}}}{T_{0}}-\dot{m}_{\mathrm{i}} \cdot T_{0} \cdot R \cdot \ln \frac{p_{\mathrm{i}}}{p_{0}}-\dot{m}_{\mathrm{j}} \cdot T_{0} \cdot c_{\mathrm{p}} \cdot \ln \frac{T_{\mathrm{j}}}{T_{0}}+\dot{m}_{\mathrm{i}} \cdot T_{0} \cdot R \cdot \ln \frac{p_{\mathrm{i}}}{p_{0}}
\end{aligned}
$$

Figure 3: Exergy flows and exergy consumption for a double stroke $(1 \rightarrow 2+2 \rightarrow 1)$ of a standard cylinder drive

Based on the determined single exergy flows an exergy flow difference between several observation points can be calculated. With regard to a defined operating task the exergy loss of each component can be determined.

The analysis of the required equations of the first and second method shows the influence of the design parameters of the drive system on the energy consumption. In particular the working pressure and the volumes of the cylinder and the tubes have a large influence.

The working pressure should be adapted on the individual requirements of each drive. In general a high pressure level increases the occurrence of leakage and total leakage mass flow. Drive systems with low requirements on the load force should be supplied with a corresponding low pressure level. The pressure level can be reduced by using a pressure regulator and increased by using a pressure booster.

The dimensioning of the components especially the choice of the piston and tube diameter has a large influence on the energy consumption. Furthermore unneeded filling volumes cause a slow dynamic behaviour.

\section{Energy saving measures}

For pneumatic single drives and multi-axes systems three categories for energy saving solutions can be distinguished. These categories concern dimensioning as well as pneumatic structures, valve technologies and control strategies. Within these categories different energy saving solutions are known [4] that are shown in the scheme in fig. 4.

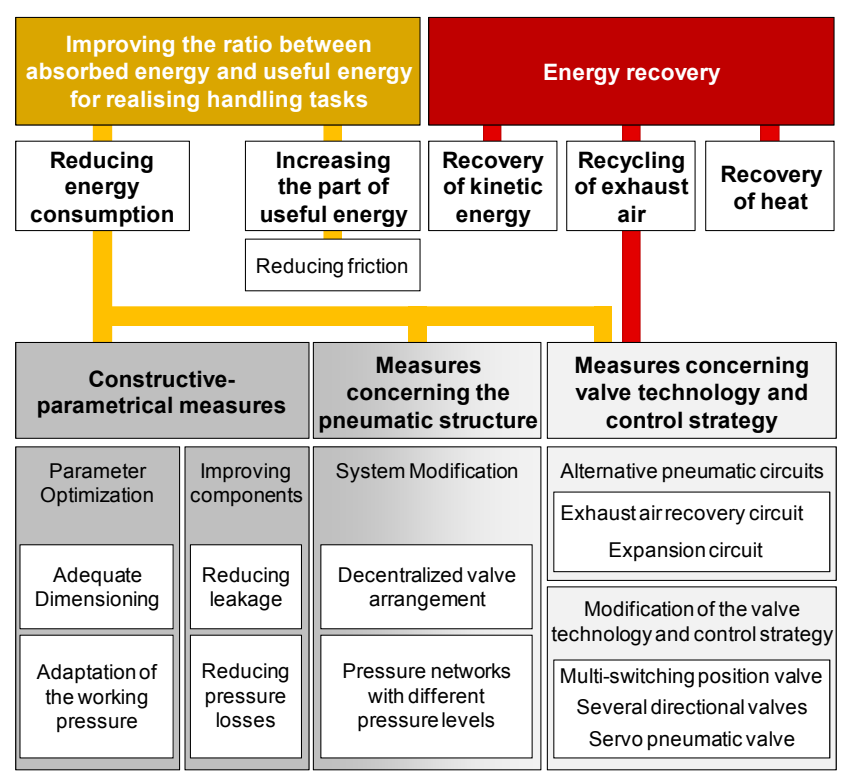

Figure 4: Energy saving measures on pneumatic drive systems

The first category <Constructive-parametrical measures $>$ contains methods for optimizing the design parameters of a drive structure or improving components meaning constructive modifications. The parameter optimization aims at the reduction of the energy consumption by modifying the design parameters of the drive. The improving of components requires the minimization of leakage and the reduction of preventable pressure drops. In most cases component modifications can be realised without any constraints but that often means a large effort concerning costs.

The second category $<$ Measures concerning the pneumatic structure $>$ contains saving solutions that target on the modification of the system structure consisting of several drives. This involves for example decentralized valve arrangements or the implementation of pressure networks with different pressure levels. For the dimensioning of different drives only a few standardized components can be used. In consequence these drives are often oversized. So it is very important to supply these drives with an appropriate pressure level. The usage of a multi-level pressure network enables an adapted compressed air supply of different drives.

The third category is "Measures concerning valve technology and control strategy". Some of these solutions with regard to valve technology are energy-saving circuit concepts like expansion- and exhaust-air recovery circuits as described in [5] and [6]. These pneumatic circuit configurations serve to utilize exhaust air which in case of standard configurations is vented unused. Further circuit- and control-based solutions aim at the modification of controland valve technology. Their goal is to minimize fundamental losses at cylinder drives. Some examples are pressure losses due to the use of exhaust-air flow control, energy emitted through exhaust air or wasted heat during the compression processes at high pressure levels. Some studies focus on circuit configurations consisting of several 2/2- 
switching valves [7]. The energy requirements of a drive system can be significantly improved, by using an optimized control strategy in combination with these switching valves. The main energy saving of this circuit structure is achieved by closing the supply valve and using the expansion energy of the compressed air during motion of the piston.

In the following potential saving measures will be implemented on a single cylinder drive of a handling system. The handling system is an automatic placement machine which is used for the placement and quality check of plug housings. The example drive system is a typical standard exhaust-air-flow-controlled cylinder drive in the field of small-part handling. The structure of the drive and some important design parameters concerning energy consumption and motion behaviour are shown in fig. 5 . The drive has a pressure supply (1), tubing (3), different valves (2), (4) and a pneumatic cylinder (5).

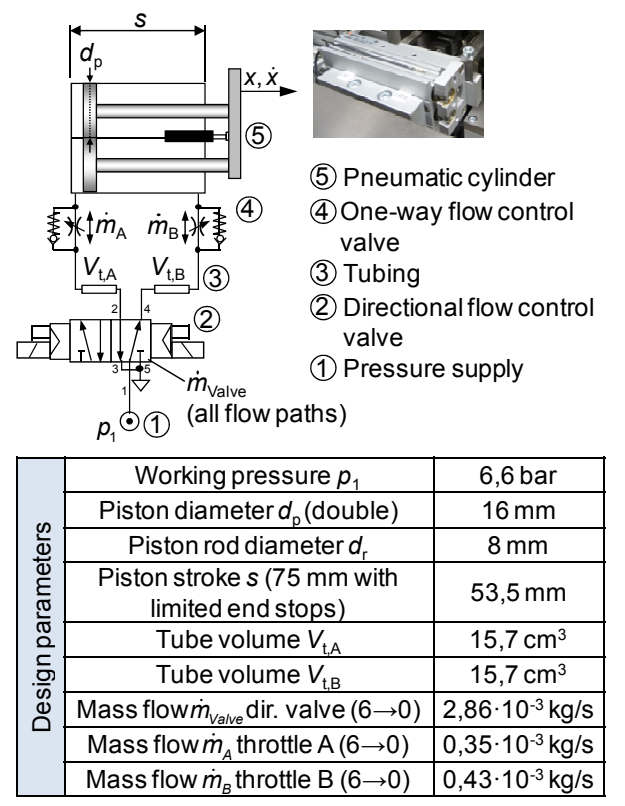

\section{Figure 5: Structure and design parameters of the example drive}

The drive is designed as a double piston cylinder with an oil brake. According to its operating task the standard configuration of the cylinder drive is oversized.

The automatic placement machine including the chosen example drive was energetically analyzed in [8]. In this process an exergy analysis according to method 2 was performed. Thereby the balancing with the exergy enables the detection of exergy losses and appropriate saving potentials. This analysis had shown that a significant energy saving potential of the machine lies in an optimized dimensioning and in the utilization of the exhaust-air of the cylinder drives. The potential of recovering the exhaust-air is even greater when an exhaust-air flow control is not used for the purpose of speed control.

After analyzing the saving potentials, a benchmark of possible energy saving measures was performed. Therefore the characteristics of these saving measures were compared to the detected energy saving potentials and the attributes of the automatic placement machine. Based on this benchmark two potential saving measures were identified i.e. the optimization of the design parameters and the use of an exhaust-air recovery circuit.

\section{Realization of energy saving measures}

In the first instance these saving measures are tested and implemented in a simulation model individually.

A lumped parameter model of the drive is created (SimulationX). The simulation model consists of different physical domains. Table 1 gives an overview of important parameters, which are required for modelling.

\section{Tab. 1: Required parameters for the simulation model}

\begin{tabular}{|c|c|}
\hline Component & Required parameters for modelling \\
\hline \multirow{4}{*}{$\begin{array}{c}\text { Pneumatic } \\
\text { cylinder }\end{array}$} & $\begin{array}{c}\text { Dimensions }(\varnothing \text { piston/rod, stroke, } \\
\text { clearance of the sealing) }\end{array}$ \\
\hline & Mass of the load (Moving mass) \\
\hline & Friction Force \\
\hline & Heat transfer coefficient $k_{\text {cylinder }}$ \\
\hline \multirow{3}{*}{$\begin{array}{l}\text { One-way flow } \\
\text { control valve }\end{array}$} & Throttle position \\
\hline & $C$-b-characteristics \\
\hline & Cracking pressure \\
\hline \multirow{3}{*}{ Tubing } & Dimensions $(\varnothing$, length $)$ \\
\hline & $C$ - $b$-characteristics \\
\hline & Heat transfer coefficient $k_{\text {tube }}$ \\
\hline \multirow{3}{*}{$\begin{array}{l}\text { Directional } \\
\text { flow control } \\
\text { valve }\end{array}$} & $C$-b-characteristics \\
\hline & switching time \\
\hline & Opening performance \\
\hline $\begin{array}{l}\text { Pressure } \\
\text { supply }\end{array}$ & Working pressure $p_{1}$ \\
\hline
\end{tabular}

The parameterisation of the components is based on data sheets, pneumatic schematics and the measurement data. Some characteristics like the throttle position of the one-way flow control valves or the friction force of the cylinders have to be calculated. For example the sliding friction of the cylinder is determined by the equilibrium of forces at the piston, when it moves with constant speed. The heat transfer coefficients at the tubing and at the cylinders can be calculated with an approximation formula [8]. The amount of leakage of the drive is relatively small and can therefore be neglected.

Firstly the optimization of the design parameter is performed at the example drive. Design parameters of the drive structure are i. e. the working pressure, the piston diameter, the length of the tubes or the flow rate of the metering throttles.

\subsection{Optimization of the design parameters}

The objective of the optimization is to reduce the energy consumption for a double stroke of the cylinder drive while sustaining the motion profile. In the first instance the range of nominal values of the design parameters will be set. The piston stroke and the flow rate at the directional valve will not be changed, since the value of the piston stroke is directly coupled to the operating task and the directional valve is part of a valve terminal with specified dimensions. The variation range of each design parameter is $\pm 25 \%$. For 
example, a reduction of the tube volume $V_{\mathrm{t}, \mathrm{a}}$ of $25 \%$ means to trim the tube length about $25 \%$. In most cases a reduction of the tube length is possible, despite constructional constraints. The definition of a variation range generally constrains the considered values of the design parameter. Thus it is possible that the parameter configuration with the lowest energy consumption of the cylinder drive (global optimum) could no longer be found. However on the basis of the suggested approach drive configurations with lower energy consumption and sufficient robustness can be found which is important for the usage in an industrial application.

In addition to the variation range of the design parameters some restrictions will be determined for the optimization process. These are obtained from the original motion profile. The cylinder drive has to fulfil its operating task according to the original operating times. The example drive is linked with other drives within the handling system. The drive's operating times have to remain constant to keep the total cycle time of the entire machine. The acceleration, the maximum velocity and the velocity at the end of the stroke are limited. In general there are different constraints with regard to manufacturer-specific limit values and the transport of handling objects. Generally the restrictions make sure that the motion profile of the modified drive is similar to the original one. The variation range of the design parameters and the restrictions are listed in tab. 2 .

Tab. 2: Variation range of the design parameters and restrictions for the optimization process

\begin{tabular}{|c|c|c|c|c|c|c|}
\hline \multirow{6}{*}{ 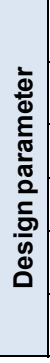 } & $\begin{array}{l}\text { Working } \\
\text { pressure } p_{1}\end{array}$ & 4,8 bar & $<$ & 6,6 bar & $<$ & 8,4 bar \\
\hline & $\begin{array}{c}\text { Piston } \\
\text { diameter } d_{p}\end{array}$ & $12,0 \mathrm{~mm}$ & $<$ & $16,0 \mathrm{~mm}$ & $<$ & $20,0 \mathrm{~mm}$ \\
\hline & Tube volume $V_{t, A}$ & $11,8 \mathrm{~cm}^{3}$ & $<$ & $15,7 \mathrm{~cm}^{3}$ & $<$ & $19,8 \mathrm{~cm}^{3}$ \\
\hline & Tube volume $V_{t, B}$ & $11,8 \mathrm{~cm}^{3}$ & $<$ & $15,7 \mathrm{~cm}^{3}$ & $<$ & $19,8 \mathrm{~cm}^{3}$ \\
\hline & $\begin{array}{l}\text { Mass flow } \dot{m}_{A} \\
\text { throttle } \mathrm{A}(6 \rightarrow 0)\end{array}$ & $0,26 \cdot 10^{-3} \mathrm{~kg} / \mathrm{s}$ & $<$ & $35 \cdot 10^{-3} \mathrm{~kg} / \mathrm{s}$ & $<$ & $4 \cdot 10^{-3} \mathrm{~kg} / \mathrm{s}$ \\
\hline & $\begin{array}{l}\text { Mass flow } \dot{m}_{B} \\
\text { throttle } B(6 \rightarrow 0)\end{array}$ & $0,32 \cdot 10^{-3} \mathrm{~kg} / \mathrm{s}$ & $<$ & $\cdot 10^{-3} \mathrm{~kg} / \mathrm{s}$ & $<$ & $4 \cdot 10^{-3} \mathrm{~kg} / \mathrm{s}$ \\
\hline \multirow{5}{*}{ 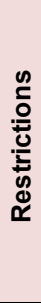 } & Extending time $t_{\mathrm{ex}}$ & $500 \mathrm{~ms}$ & $<$ & $512 \mathrm{~ms}$ & $<$ & $520 \mathrm{~ms}$ \\
\hline & Retracting time $t_{\mathrm{re}}$ & $238 \mathrm{~ms}$ & $<$ & $242 \mathrm{~ms}$ & $<$ & $248 \mathrm{~ms}$ \\
\hline & $\begin{array}{l}\text { Max. extending } \\
\text { speed } \dot{x}_{\text {ex,max }}\end{array}$ & $0,09 \mathrm{~m} / \mathrm{s}$ & $<$ & $0,11 \mathrm{~m} / \mathrm{s}$ & $<$ & $0,13 \mathrm{~m} / \mathrm{s}$ \\
\hline & $\begin{array}{l}\text { Max. retracting } \\
\text { speed } \dot{x}_{\mathrm{re}, \max }\end{array}$ & $0,25 \mathrm{~m} / \mathrm{s}$ & $<$ & $0,3 \mathrm{~m} / \mathrm{s}$ & $<$ & $0,35 \mathrm{~m} / \mathrm{s}$ \\
\hline & $\begin{array}{l}\text { Max. acceleration } \\
\ddot{x}_{\max }\end{array}$ & $25 \mathrm{~m} / \mathrm{s}^{2}$ & $<$ & $32 \mathrm{~m} / \mathrm{s}^{2}$ & $<$ & $40 \mathrm{~m} / \mathrm{s}^{2}$ \\
\hline
\end{tabular}

The optimization is done by linking the lumped parameter model with an optimization tool (OptiY). The optimization tool realizes different simulation runs with varying design parameters within the defined range. For every simulation run the amount of energy consumption after a double stroke of the drive and violations of the specified restrictions are benchmarked. Because the number of design parameters is low a gradient-based optimization strategy (Hooke-Jeeves) is chosen [9]. A nominal optimization with 500 steps is performed.
The optimization process leads to a modified cylinder drive configuration with reduced energy consumption. The final resulting design parameters are shown in tab. 3 .

\section{Tab. 3: Design parameters of the optimized cylinder drive configuration}

\begin{tabular}{|c|c|c|c|}
\hline & Standard & Optimized \\
\hline \multirow{6}{*}{ 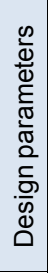 } & Working pressure $p_{1}$ & 6,6 bar & 5,0 bar \\
\hline & Piston diameter $d_{p}$ & $16 \mathrm{~mm}$ & $16 \mathrm{~mm}$ \\
\hline & Tube volume $V_{\mathrm{t}, \mathrm{A}}$ & $15,7 \mathrm{~cm}^{3}$ & $11,8 \mathrm{~cm}^{3}$ \\
\hline & Tube volume $V_{\mathrm{t}, \mathrm{B}}$ & $15,7 \mathrm{~cm}^{3}$ & $11,8 \mathrm{~cm}^{3}$ \\
\hline & $\begin{array}{c}\text { Mass flow } \dot{m}_{A} \text { throttle } \\
\mathrm{A}(6 \rightarrow 0) \\
\end{array}$ & $0,35 \cdot 10^{-3} \mathrm{~kg} / \mathrm{s}$ & $0,36 \cdot 10^{-3} \mathrm{~kg} / \mathrm{s}$ \\
\hline & $\begin{array}{c}\text { Mass flow } \dot{m}_{B} \text { throttle } \\
\mathrm{B}(6 \rightarrow 0)\end{array}$ & $0,43 \cdot 10^{-3} \mathrm{~kg} / \mathrm{s}$ & $0,46 \cdot 10^{-3} \mathrm{~kg} / \mathrm{s}$ \\
\hline
\end{tabular}

The optimized drive structure has a reduced working pressure, reduced tube volumes and the flow rate at the metering throttles is raised. For the implementation on the actual drive the working pressure has to be reduced by using a pressure regulator. Furthermore the tubes have to be trimmed and the throttle position of metering throttles has to be increased. The piston diameter remains unchanged because a change of this parameter would have a weighty influence on the motion profile and often leads to a violation of the restrictions. The simulated modified drive structure shows energy savings up to $44 \%$ (see fig. 6).
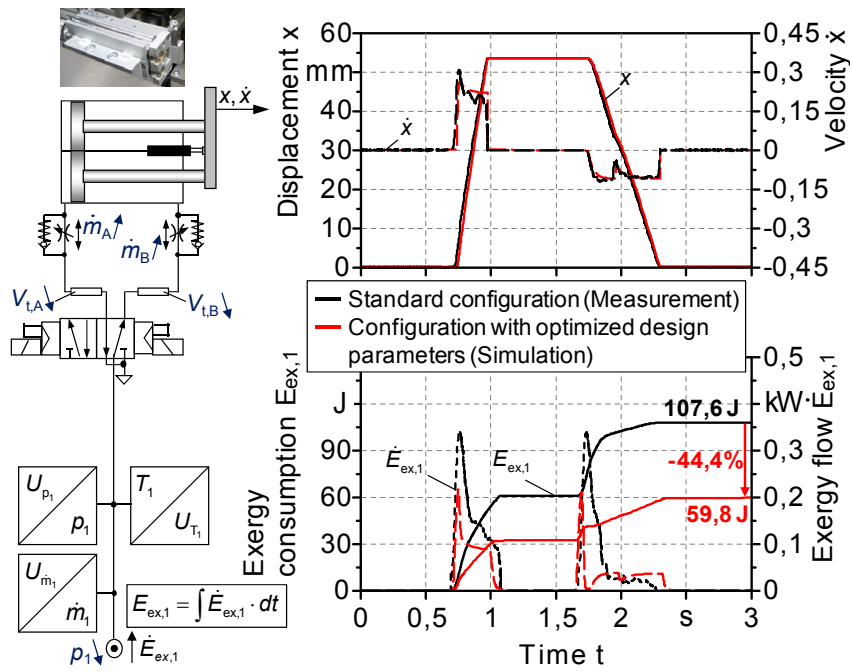

Figure 6: Energy savings using a design parameter
optimization for a standard cylinder drive

As depicted in fig. 6 the motion profile with the modified design parameters meets the original profile very well. This result shows that the restrictions were observed during the optimization process.

\subsection{Implementation of an exhaust-air recovery circuit}

An exhaust air recovery circuit can be used for drives that require only a small cylinder force for the backward stroke. For the implementation of the exhaust-air recovery system a storage circuit is added to the original configuration of the drive. There are different structural possibilities for implementing a recovery circuit. One of these circuit 
structures including its necessary valve control strategy is depicted in fig. 7.

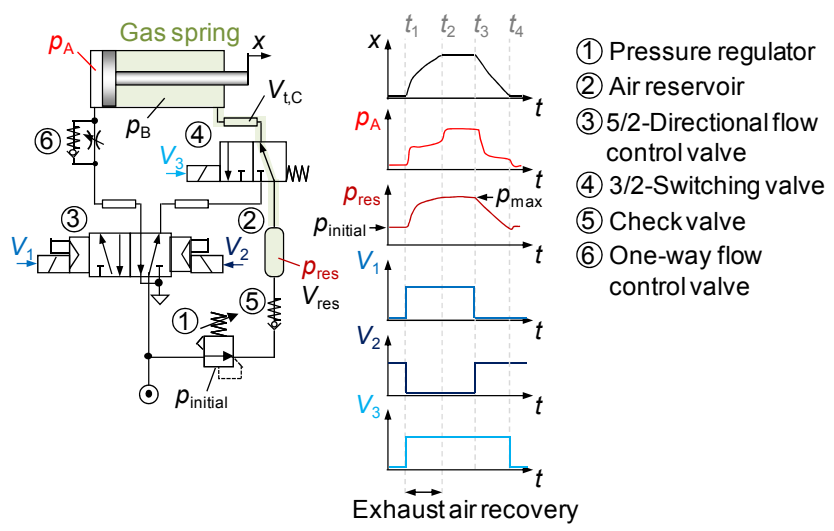

Figure 7: Structure and control strategy of the used exhaustair recovery circuit

The circuit structure shown in fig. 7 is suitable for upgrading a standard drive that is connected to a valve terminal. In general a pressure regulator (1) and an air reservoir (2) have to be installed. The initial pressure of the air reservoir is set by the pressure regulator. The control of the movement direction is executed by the 5/2-directional flow control valve (3). The 3/2-switching valve (4) connects the air reservoir to the cylinder chamber $B$. When the piston extends, the compressed air within the gas spring is compromised and the pressure $p_{\text {res }}$ rises. The check valve (5) prevents the saved compressed air of returning to the pressure regulator. At the same time the rising counterforce at the piston causes a limitation of the piston speed that eliminates the need for a metering throttle. After completing the extending stroke the saved energy is used for the backward stroke. The one-way flow control valve (6) realises the speed regulation for the backward stroke.

The initial pressure, the volume of the air reservoir and the flow rate of the metering throttle have a large influence on the motion profile of the cylinder drive. The volume of the air reservoir strongly depends on the piston diameter and the stroke. These appropriate operating parameters can be determined with the help of the simulation model with the coupled optimization tool. Table 4 lists the determined parameters for the recovery circuit.

Tab. 4: Determined design parameters of the recovery circuit

\begin{tabular}{|c|c|}
\hline Initial pressure $p_{\text {initial }}$ & 4,5 bar \\
\hline Volume of the air reservoir $V_{\text {res }}$ & $50 \mathrm{~cm}^{3}$ \\
\hline Mass flow $\dot{m}_{A}$ throttle $\mathrm{A}(6 \rightarrow 0)$ & $0,39 \cdot 10^{-3} \mathrm{~kg} / \mathrm{s}$ \\
\hline
\end{tabular}

Another way to determine the suitable volume of the air reservoir $V_{\text {res }}$ can be realised by an approximate calculation.

The volume of the gas spring $V_{\text {gas }}(\mathrm{x})$ is:

$$
\begin{gathered}
V_{\text {gas }}(\mathrm{x})=\left(\frac{\pi}{4}\left(\mathrm{~d}_{\mathrm{p}}^{2}-\mathrm{d}_{\mathrm{r}}^{2}\right) \cdot(\mathrm{s}-\mathrm{x})+\mathrm{V}_{\text {dead }, \mathrm{B}}+\mathrm{V}_{\mathrm{t}, \mathrm{C}}\right. \\
\left.+V_{\text {res }}\right)
\end{gathered}
$$

The volume of the tube $V_{\mathrm{t}, \mathrm{C}}$ and the dead volume $V_{\text {dead,B }}$ are very small and can be neglected.

Under isothermal conditions the states of the gas spring at the time $t_{1}$ with $V_{\text {gas }}(x=0 \mathrm{~mm})$ and $t_{3}$ with $V_{\text {gas }}(x=53,5 \mathrm{~mm})$ are given with:

$$
\begin{array}{cc}
t_{1}: & p_{\text {initial }} \cdot\left(\frac{\pi}{4}\left(\mathrm{~d}_{\mathrm{p}}^{2}-\mathrm{d}_{\mathrm{r}}^{2}\right) \cdot \mathrm{s}+\mathrm{V}_{\text {res }}\right)=m \cdot R \cdot T \\
t_{3}: & p_{\text {max }} \cdot \mathrm{V}_{\text {res }}=m \cdot R \cdot T
\end{array}
$$

During the time the stroke extends, the piston has to reach the end stop safely. As a conclusion the maximum pressure $p_{\max }$ of the gas spring has to be limited. A useful restriction for the maximal counterforce $F_{\mathrm{B}}$ is:

$$
F_{\mathrm{B}} \leq \frac{2}{3} \cdot p_{1} \cdot \frac{\pi}{4} \cdot d_{\mathrm{p}}^{2}
$$

In this case the maximal pressure $p_{\max }$ is:

$$
p_{\max } \leq \frac{2}{3} \cdot p_{1} \cdot \frac{d_{\mathrm{p}}^{2}}{\left(d_{\mathrm{p}}^{2}-d_{\mathrm{r}}^{2}\right)}
$$

The result for the calculation of $V_{\text {res }}$ is obtained by equalizing formula (2) and (3) and using condition (5).

$$
V_{\text {res }}=\frac{p_{\text {initial }}}{\frac{2}{3} \cdot p_{1} \cdot \frac{d_{p}^{2}}{\left(d_{\mathrm{p}}^{2}-d_{\mathrm{r}}^{2}\right)}-p_{\text {initial }}} \cdot \frac{\pi}{4}\left(\mathrm{~d}_{\mathrm{p}}^{2}-\mathrm{d}_{\mathrm{r}}^{2}\right) \cdot \mathrm{s}
$$

On the basis of eq. (6) the volume of the air reservoir $V_{\text {res }}$ can be calculated as a function of the geometric parameters of the cylinder, the working pressure $p_{1}$ and the chosen initial pressure $p_{\text {initial }}$.

The use of a recovery circuit includes higher investment costs due to the additional components. The switching valve can be excluded when using a decentralized valve arrangement. However the pressure regulator, the check valve and the air reservoir increase the investment as well as the maintenance costs.

Besides the parameters of the recovery circuit have to be adapted in case of changing operating times, load masses or cylinder parameters.

The simulation of this modified drive structure shows energy savings amounts of $43 \%$ (see fig. 8). The motion profile of the modified drive structure basically matches the original profile. The operating times are a bit higher $\left(\Delta x_{1}\right.$ and $\Delta x_{2}$, fig. 8) but don't leave the specified range. These extended operating times don't restrict the functionality of the drive. 

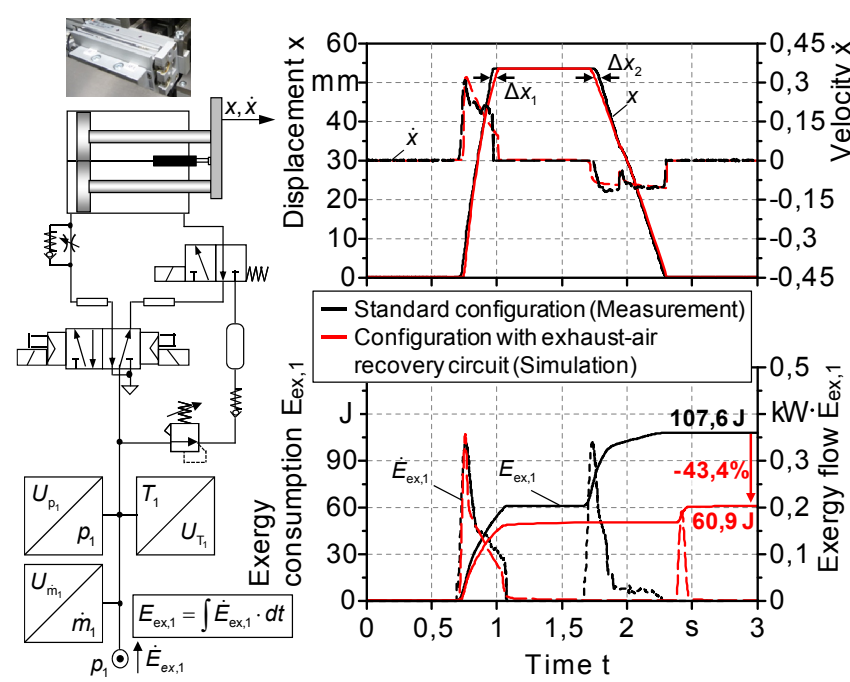

Figure 8: Energy savings using an exhaust-air recovery circuit for a standard cylinder drive

As shown in fig. 6 and fig. 8 both saving measures, e.g. the design parameter optimization and the exhaust-air recovery circuit, can reduce the energy consumption of the example drive about $44 \%$ without changing the motion profile.

\subsection{Combination of an exhaust-air recovery circuit and a design parameter optimization}

In the next step both energy saving solutions are implemented in combination at the example cylinder drive. Figure 9 compares the system behaviour of the drive, as well as the energy flow and energy consumption before and after the modification. The resulting energy savings are proven experimentally.

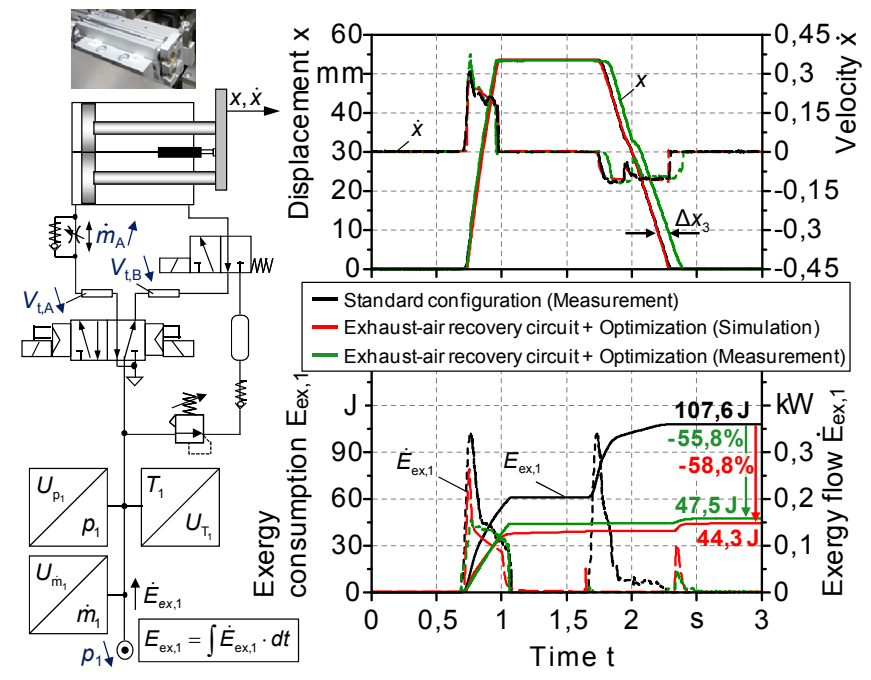

Figure 9: Resulting energy savings using an exhaust-air recovery system and a design parameter optimization for a standard cylinder drive

After the modification the motion profile shows a delay $\Delta x_{3}$ in the backward stroke of the cylinder. This will not restrict the functionality of the drive within the machine, since the backward stroke is not time-sensitive. As depicted in fig. 9 the energy saving determined by measurement data corresponds to the results of the simulation.

\section{Determination of the pay-back period}

In order to benchmark the used energy saving solutions the pay-back period has to be determined. Therefore the investment costs and the cost savings due to reduced energy costs have to be compared.

\subsection{Operating scenario and costs for compressed air}

For calculating the energy costs the number of double strokes within one year has to be specified. The selected drive is part of an entire handling system that has a total cycle time of 6 seconds. During this period the drive realises one double stroke. The handling system operates 16 hours per day. During the weekend and on maintenance days the machine remains at stand still. All in all the handling system runs 250 days per year. The number $N_{1}$ of double strokes per year is calculated in tab. 5 .

Tab. 5: Calculation of the number of double strokes per year

\begin{tabular}{|c|c|}
\hline Cycle time for one double stroke & $6 \mathrm{~s}$ \\
\hline Operating time per day & $16 \mathrm{~h}$ \\
\hline Number of double strokes per day & 57.600 \\
\hline Operating time peryear & 250 days \\
\hline Number of double strokes $N_{1}$ per year & 14.400 .000 \\
\hline
\end{tabular}

The compressed air consumption $D_{1}$ of each drive structure per double stroke can be determined via the exergy consumption under the assumption of isothermal conditions:

$$
D_{1}=\frac{E_{\mathrm{ex}, 1}}{T_{0} \cdot R \cdot \rho_{0} \cdot \ln \left(p_{1} / p_{0}\right)}
$$

In the next step the costs for generating the compressed air have to be considered. At this point an abstracted approach for the compressed air costs is chosen. The compressed air costs are $C_{\text {air }} € / \mathrm{Nl}$ ( $\mathrm{Nl}$... litre under ambient conditions). The Compressed air costs within one year can be calculated on the basis of eq. (6).

$$
\text { Compressed air costs }=N_{1} \cdot D_{1} \cdot C_{\text {air }}
$$

All costs will be referred to the compressed air costs $C_{\text {standard }}$ of the standard configuration (see tab.6).

\begin{tabular}{|c|c|c|c|c|}
\hline Drive configuration & 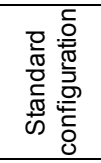 & 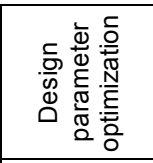 & 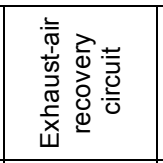 & 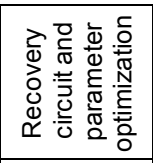 \\
\hline $\begin{array}{l}\text { Compressed air } \\
\text { consumption } D_{1} \text { per } \\
\text { double stroke }[\mathrm{NI}]\end{array}$ & 0,570 & 0,317 & 0,323 & 0,235 \\
\hline $\begin{array}{l}\text { Compressed air } \\
\text { costs peryear }[€]\end{array}$ & $C_{\text {standard }}$ & $0,56 \cdot C_{\text {standard }}$ & $0,57 \cdot C_{\text {standard }}$ & $0,41 \cdot C_{\text {standard }}$ \\
\hline $\begin{array}{c}\text { Compressed air } \\
\text { savings peryear }[€]\end{array}$ & & $-0,44 \cdot C_{\text {standard }}$ & $-0,43 \cdot C_{\text {standard }}$ & $-0,59 \cdot C_{\text {standard }}$ \\
\hline
\end{tabular}

Tab. 6: Calculated compressed air costs and savings 


\subsection{Investment costs}

The investment costs of each drive configuration are calculated as the sum of all single component investment costs. This includes the cylinder, valves, the air reservoir and end stop switches. The additional used 3/2 switching valve of the exhaust-air recovery system increases the functionality of the drive structure, but can be dropped to reduce investment costs. In the next step the additional investment costs in relation to $C_{\text {standard }}$ are determined. The results are shown in tab. 7 .

\section{Tab. 7: Calculated investment costs}

\begin{tabular}{|c|c|c|c|c|c|}
\hline \multicolumn{2}{|c|}{ Drive configuration } & \multirow[t]{2}{*}{ 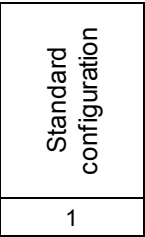 } & \multirow[t]{2}{*}{ 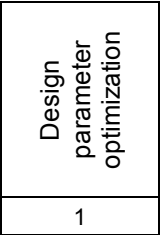 } & \multirow[t]{2}{*}{ 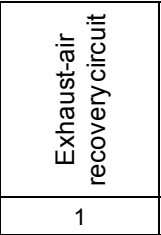 } & \multirow[t]{2}{*}{ 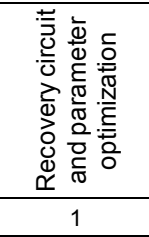 } \\
\hline \multirow{8}{*}{ 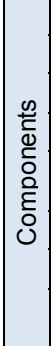 } & Cylinder & & & & \\
\hline & $5 / 2$-valve & 1 & 1 & 1 & 1 \\
\hline & $3 / 2$-valve & & & 1 & 1 \\
\hline & One-way valve & 2 & 2 & 1 & 1 \\
\hline & $\begin{array}{l}\text { Pressure } \\
\text { Regulator }\end{array}$ & & 1 & 1 & 2 \\
\hline & Checkvalve & & & 1 & 1 \\
\hline & Air reservoir & & & 1 & 1 \\
\hline & $\begin{array}{l}\text { End stop } \\
\text { switches }\end{array}$ & 2 & 2 & 2 & 2 \\
\hline \multicolumn{2}{|c|}{$\begin{array}{c}\text { Investment costs } \\
{[€]}\end{array}$} & $2,97 \cdot C_{\text {standard }}$ & $3,17 \cdot C_{\text {standard }}$ & $3,80 \cdot C_{\text {standard }}$ & $4,00 \cdot C_{\text {standard }}$ \\
\hline \multicolumn{2}{|c|}{$\begin{array}{c}\text { Additional } \\
\text { investment costs } \\
{[€]}\end{array}$} & & $+0,20 \cdot C_{\text {standard }}$ & $+0,83 \cdot C_{\text {standard }}$ & $+1,03 \cdot C_{\text {standard }}$ \\
\hline
\end{tabular}

Finally the pay-back period for each configuration can be determined. Figure 10 displays the investment costs and compressed air costs versus the operating time of the drive. The break-even point is signed with the cross. No maintenance costs as well as costs due to installation are considered.

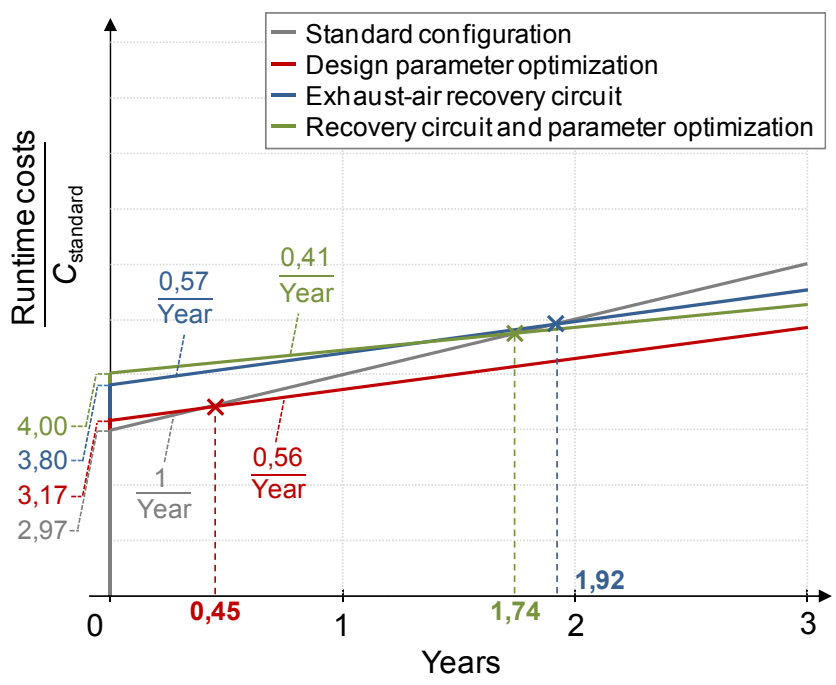

Figure 10: Determination of the pay-back periods
As shown in fig. 10 the drive configuration with the optimized design parameters has the shortest pay-back period of 0,45 years. This configuration only needs an additional pressure regulator, so the investment costs are comparable to the standard configuration. The effort on additional components for the exhaust-air recovery system is very high. The pay-back period of these drive configurations with exhaust-air recovery system lies between 1,75 to 2,00 years.

\section{Conclusion}

This article proposes energy saving measures on pneumatic drive systems. Normally investigations on energy saving measures only deal with saving potentials and functional issues. This paper presents the saving potential, the effort for implementation and the calculation of the pay-back period for two chosen energy saving solutions.

For the determination of the energy consumption two methods are presented, i.e. a compressed air consumption calculation and an exergy analysis. An exergy analysis is the preferred method because it considers all forms of energy and enables the quantification of energy losses as well as a self-contained energy balancing.

This paper shows several different measures for saving energy at pneumatic single drives and multi-axes systems. The implementation of chosen energy saving measures is tested at a representative single example drive.

The energetic analysis of this drive has successfully proven that there are two significant saving potentials. Referring to its operating task the example drive is oversized with tube lengths sized quite generously and the pressure level being too high. So the first saving method targets at an adequate dimensioning of the drive. The second saving potential lies in the utilization of the exhaust-air of the cylinder drive. This potential is even greater when an exhaust-air flow control is not used for the purpose of speed control. Based on these identified energy saving potentials, two suitable energy saving solutions are selected and implemented, i.e. an optimization of the drive's design operating parameters as well as an exhaust-air recovery system.

The implementation of these two saving measures is tested via simulation. Therefore a lumped parameter model of the drive is created and validated via measurement data. The possible energy savings when implementing the saving solutions individually as well as in combination is shown. When combining both saving measures energy savings up to $56 \%$ can be proven.

For the validation the saving measures are implemented at the example drive. In this process the effort of implementing each measure is demonstrated. The results of the experimental investigations match the results gained by simulation.

Finally the pay-back period of each saving measure is determined based on an operating scenario. The pay-back period for the design parameter optimization is 0,45 years because only one additional pressure regulator is needed. 
However the optimization process can only be done by using a coupled optimization tool. The calculated pay-back period of the drive structures with exhaust-air recovery system is less than 2 years.

As shown in this article pneumatic drive systems often hold significant saving potentials. Drive systems with energy saving solutions can utilize these potentials within a manageable pay-back period.

\section{Acknowledgement}

The content of this article was developed within the project „Verbesserung der Energieeffizienz pneumatischer Handhabungssysteme", that was funded by the Fluid Power Research Fund of VDMA, the German Engineering Federation, FKM Nr. 702520.

\section{Nomenclature}

\begin{tabular}{|c|c|c|}
\hline Designation & Denotation & Unit \\
\hline$c_{p}$ & Specific isobare heat capacity & {$[\mathrm{J} / \mathrm{kg} \cdot \mathrm{K}]$} \\
\hline$d$ & Diameter & {$[\mathrm{m}]$} \\
\hline E & Energy & {$[\mathrm{J}]$} \\
\hline$E_{e x}$ & Exergy & {$[\mathrm{J}]$} \\
\hline$\dot{E}_{e x}$ & Exergy flow & {$[\mathrm{J} / \mathrm{s}]$} \\
\hline$k$ & Thermal transmittance & {$\left[\mathrm{W} / \mathrm{m}^{2} \cdot \mathrm{K}\right]$} \\
\hline$m$ & Mass & {$[\mathrm{kg}]$} \\
\hline$\dot{m}$ & Mass flow & {$[\mathrm{kg} / \mathrm{s}]$} \\
\hline$n$ & Polytropic coefficient & - \\
\hline$p$ & Pressure & {$[\mathrm{Pa}]$} \\
\hline$p_{0}$ & Ambient pressure & {$[\mathrm{Pa}]$} \\
\hline$R$ & Specific gas constant & {$[\mathrm{J} / \mathrm{kg} \cdot \mathrm{K}]$} \\
\hline$s$ & Stroke & {$[\mathrm{m}]$} \\
\hline$T$ & Temperature & {$[\mathrm{K}]$} \\
\hline$T_{0}$ & Ambient temperature & {$[\mathrm{K}]$} \\
\hline$V$ & Volume & {$\left[\mathrm{m}^{3}\right]$} \\
\hline$x$ & Displacement & {$[\mathrm{m}]$} \\
\hline$\dot{x}$ & Velocity & {$[\mathrm{m} / \mathrm{s}]$} \\
\hline$\kappa$ & Isentropic coefficient & - \\
\hline$\rho_{0}$ & Density of the ambience & {$\left[\mathrm{kg} / \mathrm{m}^{3}\right]$} \\
\hline
\end{tabular}

\section{References}

[1] M CAI, and K Kawashima, T Kagawa. Power Assessment of Flowing Compressed Air. Published in Journal of Fluids Engineering, Transactions of the ASME, Vol.128, No.2, 2006.
[2] J Hepke, and J Weber. Energiesparende Pneumatik. fluid Markt 2013, 83-89, 2012.

[3] W T Bader, and J K Kissock. Exergy Analysis of Industrial Air Compression. Proc. from the 22th National Industrial energy Technology Conference, Houston, 2000.

[4] N N. EnEffAH - Energy Efficiency in Production in the Drive and Handling Technology Field. final report, $37-$ 44, 2012.

[5] C Ferraresi, and W Franco, and G Quaglia, and M Scopesi. Energy Saving in Pneumatic Drives: An Experimental Analysis. Proc. from the 9th International Workshop on Research and Education in Mechatronics, Bergamo, 2008.

[6] E Köhler, and E Zipplies. Pneumatische Antriebskonzepte unter dem Gesichtspunkt der Energieoptimierung und der Verbesserung der Dynamik. Proc. from Viertes Deutsch-Polnisches Seminar: Innovation und Fortschritt in der Fluidtechnik, Chemnitz, 2001.

[7] M Doll, and O Sawodny. Energy Efficient Adaptive Control of Pneumatic Drives with Switching Valves. Proc. from the 7th International Fluid Power Conference, Dresden, 2012.

[8] J Hepke, and J Weber. Improving Energy Efficiency of Pneumatic Handling Systems. Proc. from the 7th International Fluid Power Conference, Dresden, 2012.

[9] K-H Grote, and J Feldhusen. Dubbel - Taschenbuch für den Maschinenbau. 22th Edition, Springer-Verlag Berlin Heidelberg New York, D 29, 2007.

[10] H P Schwefel. Numerische Optimierung von ComputerModellen mittels der Evolutionsstrategie, Birkhäuser Verlag, Basel und Stuttgart, 1977. 